\title{
The energetics of oxygen adatoms, hydroxyl species and water dissociation on $\operatorname{Pt}(111)$
}

\author{
Eric M. Karp and Charles T. Campbell* \\ Departments of Chemical Engineering and Chemistry, University of Washington, Box 351700, \\ Seattle Washington 98195-1700, USA \\ and \\ Felix Studt, Frank Abild-Pedersen and Jens K. Nørskov \\ SUNCAT Center for Interface Science and Catalysis, SLAC National Accelerator Laboratory, \\ Menlo Park California 94025, USA \\ Department of Chemical Engineering, Stanford University, Stanford California 94305, USA
}

\begin{abstract}
Calorimetric measurements of the adsorption enthalpy of $\mathrm{O}_{2, \mathrm{~g}}$ to make $2 \mathrm{O}_{\mathrm{ad}}$ on $\mathrm{Pt}(111)$ were performed by Fiorin et al.. ${ }^{1}$ However, we show that they used a calibration value for the optical reflectivity of $\mathrm{Pt}(111)$ that was incorrectly reported in the literature. This error in reflectivity led to a $40 \%$ error in the adsorption energies originally reported. We use our more accurate reflectivity of $76 \%$ to recalibrate their oxygen adsorption enthalpy data and show that it gives nearly identical results below $0.15 \mathrm{ML}$ to the heats of adsorption determined from the temperature programmed desorption (TPD) experiments of two separate groups (Campbell et al. ${ }^{2}$ and Parker et al. ${ }^{3}$ ). Differences arise above $0.15 \mathrm{ML}$, but we attribute these to the very low sticking probability of $\mathrm{O}_{2, \mathrm{~g}}$ on $\mathrm{Pt}(111)(<0.05)$ above $0.15 \mathrm{ML}$, which can lead to large errors in the adsorption energies measured by calorimetry. Given this, we propose that the most reliable values for the adsorption enthalpy of oxygen on $\mathrm{Pt}(111)$ up to $1 / 4 \mathrm{ML}$ are those derived from TPD experiments, rather than the more recent calorimetry data. The best values are well described by (217-1510) $\mathrm{kJ} / \mathrm{mol} \mathrm{O}_{2}$ below $1 / 4 \mathrm{ML}$, where $\theta$ is the $\mathrm{O}_{a d}$ coverage in ML (i.e., $\mathrm{O}_{\text {ad }}$ per Pt surface atom). We also report calculations of coverage-dependent adsorption energies for oxygen on $\mathrm{Pt}(111)$ from density functional theory (DFT) and find the results to be an average of $21 \mathrm{~kJ} / \mathrm{mol}$ higher than the integral heats measured by TPD. We further use these corrected adsorption enthalpies to amend the energetics of hydroxyl species on $\operatorname{Pt}(111)$ that we previously measured ${ }^{4}$. This gives revised values for the standard enthalpies of formation of the coadsobed $\left(\mathrm{D}_{2} \mathrm{O}-\mathrm{OD}\right)_{\mathrm{ad}}$ complex of $-511 \pm 7 \mathrm{~kJ} / \mathrm{mol}$ and a Pt-OD bond energy of $248 \pm 7 \mathrm{~kJ} / \mathrm{mol}$ for the OD species within this complex. DFT compares reasonably well, calculating an enthalpy of formation for the $\left(\mathrm{H}_{2} \mathrm{O}-\mathrm{OH}\right)_{\text {ad }}$ complex of $-456 \mathrm{~kJ} / \mathrm{mol}$ and an O-Pt bond energy of $217 \mathrm{~kJ} / \mathrm{mol}$ for the $\mathrm{OH}$ species within this complex. These revised values are used to estimate reaction enthalpies for the dissociation of adsorbed water and hydroxyl on Pt(111), and compared to DFT.
\end{abstract}

* Corresponding author: Campbell@chem.washington.edu

\section{The enthalpy of dissociative $\mathrm{O}_{2}$ adsorption on $\operatorname{Pt}(111)$}

Beautiful calorimetric measurements of the adsorption enthalpy of $\mathrm{O}_{2, \mathrm{~g}}$ to make $2 \mathrm{O}_{\mathrm{ad}}$ on $\operatorname{Pt}(111)$ were performed by Fiorin et al.. ${ }^{1}$ However, Fischer-Wolfarth et al. ${ }^{5}$ from Schauermann and Freund's group at the Fritz-Haber Institute, in collaboration with our group, have since uncovered a systematic error in the calorimetry measurements on $\operatorname{Pt}(111)$ by Fiorin et al.. The 
error originates from their use of an incorrect value for the optical reflectivity of $\operatorname{Pt}(111)$ at 633 $\mathrm{nm}$ in calibrating the heat signal. Fiorin et al. used a reflectivity of $66 \%$ for $\operatorname{Pt}(111)$, based on an incorrectly reported value listed in the Handbook of Chemistry and Physics (see $\operatorname{ref}^{6}{ }^{6}$ ). $\operatorname{Ref}^{6}$ claims that its reflectivity values came from Weaver $\left(\mathrm{ref}^{7}\right)$ but within ref. ${ }^{7}$ the actual reflectivity of $\mathrm{Pt}$ is reported as $75 \%$.

From integrating-sphere measurements, we found the reflectivity of $\operatorname{Pt}(111)$ to be $76 \%^{8}$, very close to the values reported in Weaver's original paper ${ }^{7}$ and by Fischer-Wolfarth et al. ${ }^{5}$. If we use our more accurate reflectivity of $76 \%$ to recalibrate the oxygen adsorption enthalpy data originally reported by Fiorin et al.we obtain the corrected results versus coverage shown in Fig. 1. For comparison, we show the heat of adsorption as determined from activation energies for desorption of oxygen from $\mathrm{Pt}(111)$ measured in TPD experiments by two separate groups $\left(\right.$ Campbell et al. ${ }^{2}$ and Parker et al. ${ }^{3}$ ) with nearly identical results. Here we assume that the activation barrier for adsorption is negligibly small (as indeed reported ${ }^{3}$ ), but add the required correction of $1 / 2 \mathrm{RT}$ (where $\mathrm{T}$ is the desorption temperature) described elsewhere. ${ }^{9}$ Note the near perfect agreement between the corrected calorimetric heats of adsorption and those determined by TPD below $0.15 \mathrm{ML}$. This same correction in reflectivity applied to the calorimetric heats of adsorption for $\mathrm{CO}$ on $\operatorname{Pt}(111)$ measured by Fiorin et al. also led to near perfect agreement with our own recent calorimetric measurements for $\mathrm{CO}$ on $\mathrm{Pt}(111)$ with Fischer-Wolfarth et al. ${ }^{5}$ For $\mathrm{O}_{2}$, the difference that arises above $0.15 \mathrm{ML}$ in Fig. 1 is likely because the sticking probability of $\mathrm{O}_{2}$ on $\mathrm{Pt}(111)$ drops rapidly to $<0.05$ at $\sim 0.15 \mathrm{ML}$, making it very difficult to accurately measure adsorption energies by calorimetry. Given this, we propose that the most reliable values for the adsorption enthalpy of oxygen on $\mathrm{Pt}(111)$ are those presented in Fig. 1 derived from those TPD experiments $^{2,3}$ rather than the more recent calorimetry data, except below $0.15 \mathrm{ML}$ where they agree after this calibration correction (but were approximately $40 \%$ too high as originally reported) ${ }^{1}$.

We calculated oxygen adsorption enthalpies on $\mathrm{Pt}(111)$ for different coverages ranging from $1 / 36$ to $1 / 2$ monolayers (ML) using density functional theory(DFT), with $\mathrm{O}_{a d}$ always in 3fold hollow sites and at the greatest possible O-O separations. DFT calculations were performed using the GPAW $\operatorname{code}^{10}$, and the RPBE functional ${ }^{11}$ including zero-point energy (ZPE) corrections, with a grid spacing of $0.18 \AA$. Surfaces were modeled by four layers, where the two bottom layers were fixed to their bulk positions while the top two layers and the adsorbates were allowed to relax. A $k$-point sampling of $4 \times 4 \times 1$, and $2 \times 2 \times 1$ was used for slabs consisting of $2 \times 2$ and $3 \times 3$, and $4 \times 4$ and $6 \times 6$ Pt atoms in the $x$ and $y$ direction, respectively. The energy of gasphase $\mathrm{O}_{2}$, for which the RPBE functional performs poorly, was calculated using the DFT energies for $\mathrm{H}_{2}$ and $\mathrm{H}_{2} \mathrm{O}$ and the literature value for the reaction energy for $2 \mathrm{H}_{2}+\mathrm{O}_{2} \rightarrow 2 \mathrm{H}_{2} \mathrm{O}$, as described elsewhere ${ }^{12}$. Fig. 1 shows the integral heats of adsorption for $\mathrm{O}_{2}$ on $\operatorname{Pt}(111)$ by DFT. The calculated heat of adsorption extrapolates to $-237 \mathrm{~kJ} / \mathrm{mol}$ in the low-coverage limit, but decreases to $-217 \mathrm{~kJ} / \mathrm{mol}$ at $1 / 4 \mathrm{ML}$ and $-163 \mathrm{~kJ} / \mathrm{mol}$ at $1 / 2 \mathrm{ML}$ (Note that the adsorption energies oscillate slightly with coverage in the low coverage regime. The values presented here are calculated by the best fit curve through the adsorption energies; see Figure 1). As seen, these 
heats are $\sim 20 \mathrm{~kJ} / \mathrm{mol}$ larger than the experimental heats by TPD below $1 / 4 \mathrm{ML}$. Getman and Schneider ${ }^{13}$ also calculated coverage-dependent adsorption energies for oxygen on $\mathrm{Pt}(111)$ using DFT. Their results were $\sim 18 \mathrm{~kJ} / \mathrm{mol}$ higher than our DFT results presented in Fig. 1 but otherwise produced a nearly identical trend in adsorption enthalpy vs. coverage. The small difference may be associated with differences in the details of the calculation method and/or ZPE corrections.

\section{Using the corrected adsorption enthalpy for $\mathrm{O}_{\text {ad }}$ to revise the energetics of the $\left(\mathrm{H}_{2} \mathrm{O}\right.$ - $\mathrm{OH})_{\mathrm{ad}}$ complex and related hydroxyl species on $\mathrm{Pt}(111)$}

In our previous study of the heat of reaction of $\mathrm{D}_{2} \mathrm{O}$ with oxygen-dosed $\mathrm{Pt}(111)$, a thermodynamic cycle was constructed using measured reaction heats to calculate the standard heats of formation, $\Delta \mathrm{H}^{\mathrm{o}}$, of the coadsorbed $\left(\mathrm{D}_{2} \mathrm{O}-\mathrm{OD}\right)$ complex and adsorbed OD, and from that the $\mathrm{Pt}(111)-\mathrm{OD}$ bond enthalpy (Figure 5 within $\mathrm{ref}^{4}$ ). This cycle used a value of $-266 \mathrm{~kJ} / \mathrm{mol}$ for

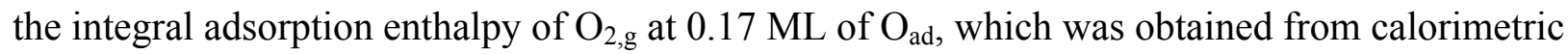
measurements on $\operatorname{Pt}(111)$ from Fiorin et al. ${ }^{1}$, but which we noted above included a calibration error. We now use these more reliable values from TPD in Fig. 1 to amend these standard enthalpies of formation of the coadsorbed $\left(\mathrm{D}_{2} \mathrm{O}-\mathrm{OD}\right)$ complex and adsorbed OD and the $\mathrm{Pt}(111)$ OD bond enthalpy we reported in ref. ${ }^{4}$. Replacing the value of $-266 \mathrm{~kJ} / \mathrm{mol}$ for the integral adsorption enthalpy of $\mathrm{O}_{2, \mathrm{~g}}$ at $0.17 \mathrm{ML}$ of $\mathrm{O}_{\mathrm{ad}}$ from the uncorrected calorimetry data of Fiorin et al. with the value of $-204 \mathrm{~kJ} / \mathrm{mol}$ from Fig. 1 based on TPD data, we obtain the improved values listed in Table 1, along with the original values reported in ref. ${ }^{4}$ for comparison. The value for $\mathrm{OD}_{\mathrm{ad}}$ within the $\left(\mathrm{D}_{2} \mathrm{O}-\mathrm{OD}\right)$ complex was estimated from $\Delta \mathrm{H}_{\mathrm{f}}^{\mathrm{o}}$ for this complex, assuming that the $\mathrm{D}_{2} \mathrm{O}$ in this complex has the same $\Delta \mathrm{H}_{\mathrm{f}}^{\mathrm{o}}$ as the most stable structure of a pure $\mathrm{D}_{2} \mathrm{O}$ adlayer, as originally done in ref. ${ }^{4}$. Table 1 also includes our calorimetric results for $\Delta \mathrm{H}_{\mathrm{f}}^{\mathrm{o}}$ of $\mathrm{D}_{2} \mathrm{O}_{\mathrm{ad}}$ in its most stable (i.e., high-coverage) structure on $\operatorname{Pt}(111)-293 \pm 7 \mathrm{~kJ} / \mathrm{mol} .{ }^{14}$ Experimental values for isolated species were estimated from these high-coverage structures by correcting for the energy change with coverage estimated from DFT (see below).

These measurements report the energetics of deuterated hydroxyl and water, from which we can also calculate the energetics of the corresponding $\mathrm{H}$ isotope by correcting for the zeropoint energy difference between Pt-OD and Pt-OH. Using known vibrational frequencies for $\mathrm{H}-$ $\mathrm{H}, \mathrm{D}-\mathrm{D}, \mathrm{O}-\mathrm{H}$ and O-D stretches ${ }^{15}$ the zero-point reaction energy difference between $\mathrm{H}_{2}+1 / 2$ $\mathrm{O}_{2} \rightarrow \mathrm{H}_{2} \mathrm{O}$ and $\mathrm{D}_{2}+1 / 2 \mathrm{O}_{2} \rightarrow \mathrm{D}_{2} \mathrm{O}$ is $5.2 \mathrm{~kJ} / \mathrm{mol}$ in the gas phase, resulting in a difference of $2.6 \mathrm{~kJ} / \mathrm{mol}$ in the heat of formation for each $\mathrm{OH}$ bond in the products (with $\mathrm{OH}$ species being less stable than the corresponding OD species). This implies that the standard heats of formation of the coadsorbed $\left(\mathrm{H}_{2} \mathrm{O}-\mathrm{OH}\right)$ complex and adsorbed $\mathrm{OH}$ should be smaller than their $\mathrm{D}$ analogues by 7.8 and $2.6 \mathrm{~kJ} / \mathrm{mol}$, respectively. Values for these $\mathrm{H}$ isotope species calculated from the D isotope results using these zero-point corrections are also listed in Table 1.

\section{DFT values for the formation enthalpies of the $\left(\mathrm{H}_{2} \mathrm{O}-\mathrm{OH}\right)_{\mathrm{ad}}$ complex and hydroxyl species on $\operatorname{Pt}(111)$}


Table 1 also includes our DFT results for the heats of formation of the coadsorbed $\left(\mathrm{H}_{2} \mathrm{O}\right.$ $\mathrm{OH}$ ) complex, adsorbed $\mathrm{H}_{2} \mathrm{O}$ and adsorbed $\mathrm{OH}$ on $\mathrm{Pt}(111)$. The results in Table 1 show that the $\left(\mathrm{H}_{2} \mathrm{O}-\mathrm{OH}\right)_{\text {ad }}$ complex is $\sim 47 \mathrm{~kJ} / \mathrm{mol}$ less stable by DFT than in the experiment, but this error drops to only $20 \mathrm{~kJ} / \mathrm{mol}$ after subtracting the enthalpy of adsorbed water to estimate the heat of formation of the $\mathrm{OH}_{\mathrm{ad}}$ within this $\left(\mathrm{H}_{2} \mathrm{O}-\mathrm{OH}\right)_{\mathrm{ad}}$ complex. Note that our calculations of $\mathrm{OH}_{\mathrm{ad}}$ in a water environment on $\mathrm{Pt}(111)$, using this same DFT method, were also found to be in good agreement with electrochemical measurements of the oxygen reduction reaction on $\mathrm{Pt}(111) .^{16,17}$ Our calculated DFT adsorption energy for high-coverage $\mathrm{H}_{2} \mathrm{O}$ is for a $\sqrt{3}$ structure at $2 / 3 \mathrm{ML}$, which is known to give a DFT adsorption energy very close to that in the more complex, slightly higher-coverage $(\sqrt{3} 9 \mathrm{x} \sqrt{ } 39) \mathrm{R} 16.1^{\circ}$ structure $^{18}$. This DFT value in Table 1 gives high-coverage $\mathrm{H}_{2} \mathrm{O}_{\text {ad }}$ to be $\sim 19 \mathrm{~kJ} / \mathrm{mol}$ less stable than the experimental value.

Experimental values for "isolated" adsorbates could not be measured but are available with DFT. To provide our best estimate of experimental values in the low-coverage limit, the measured values for the high-coverage case were corrected by adding the energy difference between this and the low-coverage limit as estimated by DFT, shown in parentheses in Table 1.

\section{Estimates of $\mathrm{O}-\mathrm{Pt}(111)$ bond enthalpies for surface $\mathrm{O}, \mathrm{OH}$ and $\mathrm{H}_{2} \mathrm{O}$, and comparison to DFT}

Table 1 also lists the experimental and DFT values for the O-Pt(111) bond enthalpies for adsorbed $\mathrm{O}_{\mathrm{ad}}, \mathrm{OH}_{\mathrm{ad}}$ and $\mathrm{H}_{2} \mathrm{O}_{\mathrm{ad}}$, calculated from the difference between their heats of formation listed here and that for the corresponding gas-phase species. Bond enthalpies to $\mathrm{Pt}(111)$ are thus defined here to include all metal-adsorbate and adsorbate-adsorbate interaction energies. As seen, the $\mathrm{O}-\mathrm{Pt}(111)$ bond enthalpy for $\mathrm{OH}_{\mathrm{ad}}$ within $\left(\mathrm{H}_{2} \mathrm{O}-\mathrm{OH}\right)_{\text {ad }}$ complex is $\sim 31 \mathrm{~kJ} / \mathrm{mol}$ weaker according to DFT than the experimental value of $248 \mathrm{~kJ} / \mathrm{mol}$; and that for $\mathrm{H}_{2} \mathrm{O}_{\text {ad }}$ is $\sim 16 \mathrm{~kJ} / \mathrm{mol}$ weaker according to DFT than the experimental value of $46 \mathrm{~kJ} / \mathrm{mol}$. The difference is most likely due to small errors in calculating the binding of $\mathrm{H}_{2} \mathrm{O}$ to the $\mathrm{Pt}(111)$ surface. Most of this interaction is due to van der Waals forces that are not described well by the functional used in this study. (When we instead used BEEF, a functional that is known to describe van der Waals interactions better ${ }^{19}$ the binding energy of $\mathrm{H}_{2} \mathrm{O}$ to the $\mathrm{Pt}(111)$ surface in the low coverage regime increases by $24 \mathrm{~kJ} / \mathrm{mol}$, much closer to experiment.)

\section{Enthalpies for reactions involving surface hydroxyls on $\operatorname{Pt(111)}$}

The enthalpies of formation in Table 1 allow us to estimate reaction enthalpies $\left(\Delta \mathrm{H}_{\mathrm{rxn}}^{\mathrm{o}}\right)$ for the following reactions involving surface hydroxyls on $\operatorname{Pt}(111)$ :

$$
\begin{array}{lll}
\mathrm{H}_{2} \mathrm{O}_{\mathrm{ad}} \rightarrow \mathrm{OH}_{\mathrm{ad}}+\mathrm{H}_{\mathrm{ad}} & \Delta \mathrm{H}^{0}{ }_{1}=45 \mathrm{~kJ} / \mathrm{mol}, \\
\mathrm{OH}_{\mathrm{ad}} \rightarrow \mathrm{O}_{\mathrm{ad}}+\mathrm{H}_{\mathrm{ad}} & \Delta \mathrm{H}^{0}{ }_{2}=62 \mathrm{~kJ} / \mathrm{mol},
\end{array}
$$

and

$$
2 \mathrm{OH}_{\mathrm{ad}} \rightarrow \mathrm{O}_{\mathrm{ad}}+\mathrm{H}_{2} \mathrm{O}_{\mathrm{ad}} \quad \Delta \mathrm{H}_{3}^{0}=17 \mathrm{~kJ} / \mathrm{mol}
$$


The values listed above were calculated using the experimental values of $\Delta \mathrm{H}_{\mathrm{f}}^{\mathrm{o}}$ each adsorbate in its most stable structures, which for $\mathrm{O}_{a d}$ and $\mathrm{H}_{a d}$ are the low-coverage limits, but for $\mathrm{H}_{2} \mathrm{O}_{a d}$ is its high-coverage structure and for $\mathrm{OH}_{\mathrm{ad}}$ is in the $\left(\mathrm{H}_{2} \mathrm{O}-\mathrm{OH}\right)_{\mathrm{ad}}$ complex. These elementary steps have been proposed to take place in many important catalytic reactions over Pt. Note that Reactions (1) and (2) are rather endothermic, and therefore probably rather slow steps in these catalytic mechanisms.

Table 2 summarizes these reaction energies, and compares them to values based on DFT energies and values for the adsorbates in their low-coverage limit, estimated as described. The energy for Reaction (1) is accurately estimated with DFT, but Reaction (2) is less uphill by 27 $\mathrm{kJ} / \mathrm{mol}$, and Reaction (3) is estimated to be $14 \mathrm{~kJ} / \mathrm{mol}$ exothermic by DFT, but $17 \mathrm{~kJ} / \mathrm{mol}$ endothermic experimentally.

The reaction energies is Table 1 can also be compared to earlier DFT calculations by Mavrikakis's group, who found the following energies for Reactions (1) through (3) at 1/4ML coverage of $50 \mathrm{~kJ} / \mathrm{mol}, 15 \mathrm{~kJ} / \mathrm{mol}$, and $-36 \mathrm{~kJ} / \mathrm{mol}$, respectively. ${ }^{20}$

In summary, we corrected the enthalpy of $\mathrm{O}_{2}$ adsorption using our more accurate reflectivity of $76 \%$ and show that it gives nearly identical results below $0.15 \mathrm{ML}$ to the heats of adsorption determined from TPD experiments. ${ }^{2,3}$ We further use these corrected adsorption enthalpies to amend the energetics of hydroxyl species on $\mathrm{Pt}(111)$ that we previously measured ${ }^{21}$, giving revised values for the standard enthalpies of formation of the coadsorbed $\left(\mathrm{H}_{2} \mathrm{O}-\mathrm{OH}\right)$ complex of $-503 \pm 7 \mathrm{~kJ} / \mathrm{mol}$. From this, we estimate a O-Pt(111) bond enthalpy in adsorbed hydroxyl of $248 \pm 7 \mathrm{~kJ} / \mathrm{mol}$ within this complex. This value is an upper bound, since it assumes that the $\mathrm{H}$-bonding interactions between $\mathrm{OH}_{\mathrm{ad}}$ and $\mathrm{H}_{2} \mathrm{O}_{\mathrm{ad}}$ are the same in the complex as in a pure $\mathrm{H}_{2} \mathrm{O}$ adlayer, but the very fact that $\mathrm{OH}_{\mathrm{ad}}$ and $\mathrm{H}_{2} \mathrm{O}_{\mathrm{ad}}$ combine into a stable 1:1 complex proves they are more stable in the complex. Using the difference in DFT values for the O-Pt(111) bond enthalpies for $\mathrm{OH}_{\mathrm{ad}}$ of $217 \mathrm{~kJ} / \mathrm{mol}$ within the $\left(\mathrm{H}_{2} \mathrm{O}-\mathrm{OH}\right)$ complex (estimated with this same assumption) and of $179 \mathrm{~kJ} / \mathrm{mol}$ for isolated $\mathrm{OH}_{\mathrm{ad}}$ to approximately correct this assumption gives an estimate of $210 \pm 7 \mathrm{~kJ} / \mathrm{mol}$ for the experimentally measured O-Pt(111) bond strength in isolated $\mathrm{OH}_{\mathrm{ad}}$. These revised values are used to estimate reaction enthalpies for the dissociation of adsorbed water and hydroxyl on Pt(111). The DFT value for water is in good agreement, but the DFT value for $\mathrm{OH}_{\mathrm{ad}}$ dissociation is $27 \mathrm{~kJ} / \mathrm{mol}$ less endothermic 
Table 1. Standard enthalpies of formation at $298 \mathrm{~K}\left(\Delta \mathrm{H}_{\mathrm{f}}^{\mathrm{o}}\right)$ of $\mathrm{O}$ adatoms, adsorbed hydroxyl and the coadsorbed hydroxyl-water complex (both D and $\mathrm{H}$ isotopes) on $\mathrm{Pt}(111)$ at the specified coverages, and the corresponding O-Pt(111) bond enthalpies calculated from the corrected enthalpy of $\mathrm{O}_{2}$ adsorption (TPD-based data in Fig. 1) and the thermodynamic cycle of Figure 5 within ref. ${ }^{4}$. Numbers in italics are the original values reported in ref. ${ }^{4}$ before correction (which in the case of $\mathrm{O}_{\mathrm{ad}}$ corresponds to the uncorrected heats originally reported by Fiorin et al. ${ }^{1}$ ). Values for $\mathrm{OD}_{\mathrm{ad}}$ and $\mathrm{OH}_{\mathrm{ad}}$ were estimated from the values for the corresponding hydroxyl-water complex, assuming that the water in this complex has the same heat of formation as the most stable structure of a pure water adlayer, as describe in ref. ${ }^{4}$. Conversion of experimental enthalpies, which were all for the $\mathrm{D}$ isotope, to the $\mathrm{H}$ isotope used the known difference in zeropoint energies, as described in text. 


\begin{tabular}{|c|c|c|c|c|c|}
\hline Adsorbate & $\begin{array}{c}\text { Coverage } \\
\text { (ML) }\end{array}$ & $\begin{array}{c}\text { Experimental } \\
\Delta \mathbf{H}_{\mathbf{f}}^{\mathbf{0}} \\
(\mathbf{k J} / \mathbf{m o l})\end{array}$ & $\begin{array}{c}\text { O-Pt(111) } \\
\text { Bond } \\
\text { Enthalpy } \\
\text { (kJ/mol) }\end{array}$ & $\begin{array}{c}\text { DFT } \\
\Delta \mathbf{H}_{\mathrm{f}}^{\mathbf{f}} \\
(\mathbf{k J} / \mathbf{m o l})\end{array}$ & $\begin{array}{c}\text { DFT } \\
\text { O-Pt(111) } \\
\text { Bond } \\
\text { Enthalpy } \\
\text { (kJ/mol) }\end{array}$ \\
\hline \multirow{3}{*}{$\mathrm{O}_{\mathrm{ad}}$} & $0 \mathrm{ML}$ & $\begin{array}{l}-109 \pm 7 \\
(-150 \pm 7)\end{array}$ & $358 \pm 7^{*}$ & -119 & -362 \\
\hline & $0.17 \mathrm{ML}$ & $\begin{array}{l}-102 \pm 7 \\
(-133 \pm 7)\end{array}$ & $351 \pm 7^{*}$ & -114 & -357 \\
\hline & $0.25 \mathrm{ML}$ & $\begin{array}{c}-99 \pm 7 \\
(-125 \pm 7) \\
\end{array}$ & $348 \pm 7^{*}$ & -109 & -352 \\
\hline$\left(\mathrm{D}_{2} \mathrm{O}-\mathrm{OD}\right)_{\mathrm{ad}}$ & $1 / 3 \mathrm{ML}$ & $\begin{array}{c}-511 \pm 7 \\
(-527 \pm 7)\end{array}$ & - & - & - \\
\hline$\left(\mathrm{H}_{2} \mathrm{O}-\mathrm{OH}\right)_{\mathrm{ad}}$ & 1/3 ML & $-503 \pm 7$ & - & -456 & - \\
\hline $\begin{array}{c}\mathrm{OD}_{\mathrm{ad}} \text { within } \\
\left(\mathrm{D}_{2} \mathrm{O}-\mathrm{OD}\right)_{\mathrm{ad}} \\
\text { complex } \\
\end{array}$ & $1 / 3 \mathrm{ML}$ & $\begin{array}{c}-210 \pm 7 \\
(-226 \pm 7)\end{array}$ & $\begin{array}{c}248 \pm 7 \\
(263 \pm 7)\end{array}$ & - & - \\
\hline $\begin{array}{c}\mathrm{OH}_{\mathrm{ad}} \text { within } \\
\left(\mathrm{H}_{2} \mathrm{O}-\mathrm{OH}\right)_{\mathrm{ad}} \\
\text { complex }\end{array}$ & $1 / 3 \mathrm{ML}$ & $-207 \pm 7$ & $248 \pm 7$ & -187 & $217 * *$ \\
\hline $\begin{array}{c}\mathrm{D}_{2} \mathrm{O}_{\mathrm{ad}} \\
\text { High } \\
\text { Coverage }\end{array}$ & $\sim 2 / 3 \mathrm{ML}$ & $-293 \pm 7$ & $51.3 \pm 7$ & - & - \\
\hline $\begin{array}{c}\mathrm{H}_{2} \mathrm{O}_{\mathrm{ad}} \\
\text { High } \\
\text { Coverage }\end{array}$ & $\sim 2 / 3 \mathrm{ML}$ & $-288 \pm 7$ & $46.2 \pm 7$ & -269 & 30 \\
\hline $\begin{array}{l}\mathrm{H}_{2} \mathrm{O}_{\mathrm{ad}} \\
\text { Isolated }\end{array}$ & 1/16 ML & $(-268 \pm 7)^{* * *}$ & $(26.2 \pm 7)^{* * *}$ & -249 & 10 \\
\hline $\begin{array}{c}\mathrm{OH}_{\mathrm{ad}} \\
\text { Isolated }\end{array}$ & $1 / 16 \mathrm{ML}$ & $(-169 \pm 7)^{* * *}$ & $(210 \pm 7)^{* * *}$ & -149 & $179^{* *}$ \\
\hline $\begin{array}{c}\mathrm{H}_{\mathrm{ad}} \\
\text { Isolated }\end{array}$ & $\sim 1 / 16 \mathrm{ML}$ & -36 & - & -33 & - \\
\hline
\end{tabular}

* The bond enthalpies listed here for $\mathrm{O}_{\mathrm{ad}}$ are the entire O-Pt(111) bond enthalpy, which sums the bonding to three $\mathrm{Pt}$ atoms since $\mathrm{O}_{\mathrm{ad}}$ sits in a 3-fold hollow site. ${ }^{22}$ We use here the known standard heat of formation of $\mathrm{O}_{\mathrm{g}}$ of $249.2 \pm 0.1 \mathrm{~kJ} / \mathrm{mol}^{23}$ Bond enthalpies for adsorbed hydroxyl and water to $\mathrm{Pt}(111)$ are defined here to include all adsorbate-adsorbate interaction energies. ** This uses the DFT value for $\Delta \mathrm{H}_{\mathrm{f}}^{\mathrm{o}}\left(\mathrm{OH}_{\mathrm{g}}\right)$ of $30.3 \mathrm{~kJ} / \mathrm{mol}$. (The experimental value is 39.0 $\mathrm{kJ} / \mathrm{mol})^{24}$

*** The experimental values for "isolated" adsorbates are written in parentheses here, since they were estimated by correcting the measured value for the high-coverage case by adding the energy difference between this and the low-coverage limit as estimated by DFT. 
Table 2. Reaction enthalpies $\left(\Delta \mathrm{H}^{\mathrm{o}}{ }_{\mathrm{rxn}}\right)$ on $\mathrm{Pt}(111)$ for three reactions involving adsorbed $\mathrm{OH}$, comparing experimental values with those estimated by DFT on $\operatorname{Pt}(111)$ terraces. These reaction heats were calculated from the heats of formation of all the adsorbates in two situations with respect to surface coverage: in their lowest-coverage state and in their most stable situation, which for $\mathrm{H}_{2} \mathrm{O}_{\mathrm{ad}}$ corresponds to the high-coverage pure water adlayer and for $\mathrm{OH}_{\mathrm{ad}}$ corresponds to its presence in the coadsorbed $\left(\mathrm{H}_{2} \mathrm{O}-\mathrm{OH}\right)$ complex, assuming that the water in this complex has the same heat of formation as in that most stable pure water adlayer. (Note that this "most stable" case is equivalent to replacing each $\mathrm{OH}_{\mathrm{ad}}$ in each reaction as written below with $\left(\mathrm{H}_{2} \mathrm{O}\right.$ $\mathrm{OH})_{\mathrm{ad}}$, and adding an $\mathrm{H}_{2} \mathrm{O}_{\mathrm{ad}}$ to the other side of the reaction, which is a more rigorous way to represent these reaction in that case.) The experimental values were only determined in this "most stable" situation. The experimental low-coverage limits are written in parentheses here, since they were estimated by correcting this $\Delta \mathrm{H}^{\mathrm{o}}{ }_{\text {rxn }}$ value for the most stable case by adding the difference in $\Delta \mathrm{H}^{\mathrm{o}}$ rxn between this and the low-coverage limit as estimated by DFT.

\begin{tabular}{|c|c|c|c|}
\hline \multicolumn{1}{|c|}{ Reaction } & Coverage & $\begin{array}{c}\text { Experimental } \\
\Delta \mathbf{H}_{\mathbf{r x n}} \\
(\mathbf{k J} / \mathbf{m o l})\end{array}$ & $\begin{array}{c}\text { DFT } \\
\mathbf{\Delta} \mathbf{H}_{\mathbf{r x n}} \\
\mathbf{( k J / m o l})\end{array}$ \\
\hline \multirow{2}{*}{$\mathrm{H}_{2} \mathrm{O}_{\mathrm{ad}} \rightarrow \mathrm{OH}_{\mathrm{ad}}+\mathrm{H}_{\mathrm{ad}}$} & $\begin{array}{c}\text { Low-Coverage } \\
\text { Limits }\end{array}$ & 67 \\
\cline { 2 - 4 } & $\begin{array}{c}\text { Most Stable } \\
\text { Adsorbates }\end{array}$ & 45 & 49 \\
\hline \multirow{2}{*}{$\mathrm{OH}_{\mathrm{ad}} \rightarrow \mathrm{O}_{\mathrm{ad}}+\mathrm{H}_{\mathrm{ad}}$} & $\begin{array}{c}\text { Low Coverage } \\
\text { Limits }\end{array}$ & $(24)$ & -3 \\
\cline { 2 - 4 } & $\begin{array}{c}\text { Most Stable } \\
\text { Adsorbates }\end{array}$ & 62 & 35 \\
\hline \multirow{2}{*}{$2 \mathrm{OH}_{\mathrm{ad}} \rightarrow \mathrm{O}_{\mathrm{ad}}+\mathrm{H}_{2} \mathrm{O}_{\mathrm{ad}}$} & $\begin{array}{c}\text { Low-Coverage } \\
\text { Limits }\end{array}$ & $(-39)$ & -70 \\
\cline { 2 - 4 } & $\begin{array}{c}\text { Most Stable } \\
\text { Adsorbates }\end{array}$ & 17 & -14 \\
\hline
\end{tabular}




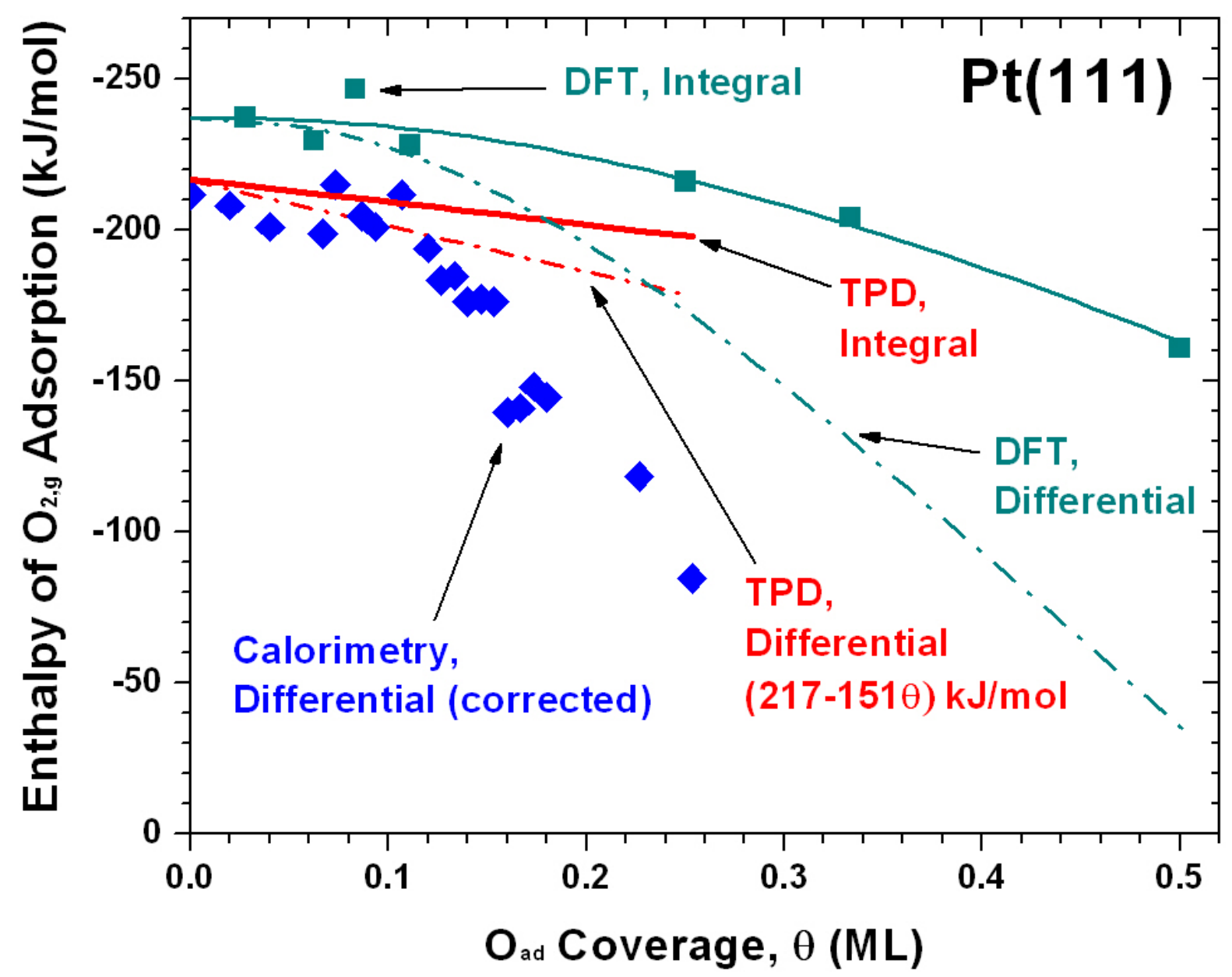

Figure 1. The enthalpy of $\mathrm{O}_{2, \mathrm{~g}}$ adsorption on $\mathrm{Pt}(111)$ versus $\mathrm{O}_{\mathrm{ad}}$ coverage measured by Fiorin et al. using single crystal adsorption calorimetry ${ }^{1}$, after correction for an error in reflectivity as described in text (filled diamonds) compared to that determined from the TPD experiments of ref ${ }^{2}$ and $^{3}$ (solid line). We have averaged the TPD measurements of ref $^{2}$ and ${ }^{3}$ and added $1 / 2$ RT for direct comparison to adsorption enthalpies, as described in text, giving $\Delta \mathrm{H}_{\mathrm{ads}}=(217-151 \theta)$ $\mathrm{kJ} / \mathrm{mol}$, where $\theta$ is the coverage. Also presented is the integral heat of adsorption calculated by DFT as a function of coverage (filled squares) and, for comparison, the integral heat of adsorption from TPD (dashed line). The inset focuses on the region from 0 to $0.25 \mathrm{ML}$ of $\mathrm{O}_{\mathrm{ad}}$ coverage, which is the maximum coverage reached in most ultrahigh vacuum experiments. 


\section{CITATIONS}

(1) Fiorin, V.; Borthwick, D.; King, D. A. Surface Science 2009, 603, 1360.

(2) Campbell, C. T.; Ertl, G.; Kuipers, H.; Segner, J. Surface Science 1981, $107,220$.

(3) Parker, D. H.; Bartram, M. E.; Koel, B. E. Surface Science 1989, 217, 489.

(4) Lew, W.; Crowe, M. C.; Karp, E.; Lytken, O.; Farmer, J. A.; Arnadottir, L.; Schoenbaum, C.; Campbell, C. T. Journal of Physical Chemistry C 2011, 115, 11586.

(5) Fischer-Wolfarth, J. H.; Hartmann, J.; Farmer, J. A.; Flores-Camacho, J. M.; Campbell, C. T.; Schauermann, S.; Freund, H. J. Review of Scientific Instruments 2011, $82,15$.

(6) Weaver, J. H.; Frederikse, H. P. R. In CRC; CRC Press: Boca Raton, Fl, 2008, p 12.

(7) Weaver, J. H. Physical Review B 1975, 11, 1416.

(8) Ihm, H.; Ajo, H. M.; Gottfried, J. M.; Bera, P.; Campbell, C. T. Journal of Physical Chemistry B 2004, 108, 14627.

(9) Brown, W. A.; Kose, R.; King, D. A. Chemical Reviews 1998, 98, 797.

(10) Enkovaara, J.; Rostgaard, C.; Mortensen, J. J.; Chen, J.; Dulak, M.;

Ferrighi, L.; Gavnholt, J.; Glinsvad, C.; Haikola, V.; Hansen, H. A.; Kristoffersen, H. H.; Kuisma, M.; Larsen, A. H.; Lehtovaara, L.; Ljungberg, M.; Lopez-Acevedo, O.; Moses, P. G.; Ojanen, J.; Olsen, T.; Petzold, V.; Romero, N. A.; Stausholm-Moller, J.; Strange, M.; Tritsaris, G. A.; Vanin, M.; Walter, M.; Hammer, B.; Hakkinen, H.; Madsen, G. K. H.; Nieminen, R. M.; Norskov, J.; Puska, M.; Rantala, T. T.; Schiotz, J.; Thygesen, K. S.; Jacobsen, K. W. Journal of Physics-Condensed Matter 2010, 22, 24.

7413.

(11) Hammer, B.; Hansen, L. B.; Norskov, J. K. Physical Review B 1999, 59,

(12) Rossmeisl, J.; Logadottir, A.; Norskov, J. K. Chemical Physics 2005, 319,

178.

(13) Getman, R. B.; Schneider, W. F. Chemcatchem 2010, 2, 1450.

(14) Lew, W. D.; Crowe, M. C.; Karp, E.; Campbell, C. T. Journal of Physical Chemistry C 2011, 115, 9164.

(15) McQuarrie, D. A. Statistical mechanics; University Science Books:

Sausalito, Calif., 2000.

(16) Stamenkovic, V. R.; Fowler, B.; Mun, B. S.; Wang, G. F.; Ross, P. N.;

Lucas, C. A.; Markovic, N. M. Science 2007, 315, 493.

(17) Rossmeisl, J.; Karlberg, G. S.; Jaramillo, T.; Norskov, J. K. Faraday Discussions 2008, 140, 337.

(18) Meng, S.; Xu, L. F.; Wang, E. G.; Gao, S. W. Physical Review Letters 2003, 91 .

(19) Wellendorff, J.; Lundgaard, K. T.; Møgelhøj, A.; V. Petzold, V.; Landis, D. D.; Nørskov, J. K.; Bligaard, T.; Jacobsen, K. W. Physical Review B. In Press 2012.

(20) Grabow, L. C.; Gokhale, A. A.; Evans, S. T.; Dumesic, J. A.; Mavrikakis, M. Journal of Physical Chemistry C 2008, 112, 4608.

(21) FootNote4.

(22) Jerdev, D. I.; Kim, J.; Batzill, M.; Koel, B. E. Surface Science 2002, 498, L91. 
(23) Cox, J. D.; Wagman, D. D.; Medvedev, V. A.; Hemisphere Pub. Corp.: New York, 1989.

(24) Chase, M. W.; National Institute of Standards and, T. NIST-JANAF thermochemical tables; American Chemical Society; American Institute of Physics for the National Institute of Standards and Technology: [Washington, D.C.]; Woodbury, N.Y., 1998.

(a) 